\title{
Correlations Between Indigenous Mycoparasitic and Symbiotic Beneficial Fungi at Heavy Metal Stress
}

\author{
${ }^{1}$ Z. NAÁR, ${ }^{1}$ F. ROMÁN and ${ }^{2}$ A. FÜZY \\ ${ }^{1}$ Eszterházy Károly College, Eger and ${ }^{2}$ Research Institute for Soil Science and \\ Agricultural Chemistry (RISSAC) of the Hungarian Academy of Sciences, Budapest
}

Among the rhizosphere colonizing microbes of higher plants, beneficial fungi, such as the symbiotic arbuscular mycorrhizal- (AM) or free-living mycoparasitic (Trichoderma) fungi are the most prominent. Trichoderma species are among those saprophytic microbes that are often studied in relation to their influence on other microbes in soils. The main reason of this is that Trichoderma fungi are antagonistic against several soil-borne plant pathogens, thus are promising tools of biological control (PAPAVIZAS, 1985). However, the introduction of an active mycoparasitic microorganism into the soil in high amount may be deleterious also for the other beneficial, but symbiotic mycorrhizal fungi (AMF). The mycorrhiza-Trichoderma relationships have been studied poorly, thus the published results are contradictory (GRYNDLER et al., 1996; WYSS et al., 1992). ROUSSEAU et al. (1996) observed that a selected strain of T. harzianum could aggressively parasitize Glomus intraradices in the rhizosphere. The positive effect of Trichoderma on mycorrhiza infection frequency was demonstrated (CALVET et al., 1992; GODEAS et al., 1999; TSIMILLI-MICHAEL et al., 2000). Synergistic relationships were recorded on the biomass of mycorrhizal plants in the presence of both fungal partners (CALVET et al., 1992).

There are very few data about the effect of heavy metals on the antagonistic activity of Trichoderma fungi. Short-term heavy metal stress strongly decreased the growth of Trichoderma spp., but their hydrolytic enzymes contributing to their activity remained active (KREDICS et al., 2001a,b). The breeding of Trichoderma spp. for heavy metal resistance showed that the highly antagonistic strains adapted to heavy metal stress easily and the frequently found mutants retained their mycoparasitic activity (KREDICS et al., 2001c).

According to our knowledge, information is rather scarce about the influence of indigenous Trichoderma fungi on native mycorrhizal formation and function, especially in correlation with long-term heavy metal pollution. The aim of our study, therefore, was to assess the interrelations between the natural Tricho-

Correspondence to: Dr. Zoltán NAÁR, Eszterházy Károly College, Department of Botany, H-3301 Eger, Eszterházy tér 1. Hungary. E-mail: naarzo@ektf.hu 
derma populations and endomycorrhiza colonization properties at various rates of a long-term heavy metal pollution.

\section{Materials and Methods}

\section{Soil treatment and plant growth}

Soil samples originated from a pot experiment in which red clover (Trifolium pratense $L$.) was grown as test plant in a controlled light chamber. The calcareous chernozem soil $\left(\mathrm{pH}(\mathrm{KCl})\right.$ : $7.2 ; \mathrm{CaCO}_{3}$ content: $5.5 \%$; humus content: $3 \%$; sand:silt:clay ratio 2:2:1) was artificially loaded in situ (Experimental Station of RISSAC, Nagyhörcsök) with salts of tested elements at rates of 90, 270 and 810 $\mathrm{kg} \cdot \mathrm{ha}^{-1}$ (i.e. $30,90,270 \mathrm{mg} \cdot \mathrm{kg}^{-1}$ dry soil). Soil samples from the long-term field experiment without any preliminary metal treatment served as control. Red clover plants were grown in greenhouse for three months before the determination of dry matter production and metal content. Further details of the experimental background and heavy metal loads are discussed by KÁDÁR (1995).

\section{Assessment of the colonization of beneficial fungi in the rhizosphere}

Soil particles $(\sim 1-2 \mathrm{~mm})$ originating from the metal loaded soils were placed on a Trichoderma-selective agar according to the suggestions of ASKEW \& LAING (1993). Three agar plates containing 30 particles each were incubated for 14 days at room temperature and the rate of colonization was also recorded. Purified isolates were maintained on potato-dextrose agar (PDA) slants until identification according to RIFAI (1969) and BISSETT (1991a-c, 1992). Frequency of species was also recorded as the ratio of colonized soil particles, and the Shannon diversity index was computed for each heavy metal treatment.

Mycorrhizal parameters (infection frequency $-F \%$ and relative or absolute arbusculum richness $-a \%, A$, respectively) were calculated after a dissecting microscopic investigation of the aniline-stained clover roots, as it was stated in the paper of VöRÖS et al. (1998).

\section{Statistical analyses}

Means of colony forming unit data at various heavy metal treatments were distinguished by analysis of variance. Relationships between Trichoderma and mycorrhizal parameters were estimated by correlation analysis. Partial correlation analysis was performed to eliminate the effect of heavy metal pollution on mycorrhizal parameters and to demonstrate their direct relationship with Trichoderma. The complex influence of Trichoderma fungi on mycorrhizal colonization data was computed with multiple correlation analysis using Statgraphics 5.1 software. 


\section{Results}

Correlations of single Trichoderma parameters with mycorrhizal colonization data

The correlation between Trichoderma and arbuscular mycorrhizal parameters was studied in heavy metal treatments. The available metal content was considered as described in VÖRÖS et al. (1998).

In Cd-polluted soils most Trichoderma parameters correlated positively with the mycorrhizal ones (Table 1). Correlation coefficients (obtained with partial correlations for eliminating the effect of heavy metals) were rather variable, ranging from -0.999 to 0.892 . Significant distances $(>1.0)$ were found between the full and partial correlation coefficients for F\%, which suggested that Cdpollution markedly influenced the relationship between Trichoderma and AMF. However, the similar values for a\% indicated that the intraradical activity of AMF was not significantly affected by Trichoderma.

The similar correlation coefficients showed that Ni pollution did not influence the relationship of Trichoderma and AMF. The population density of $T$. viride (data not shown) negatively correlated both with the infection frequency (F \%) and arbusculum richness (a \%).

Table 1

Correlations and partial correlations between Trichoderma (diversity, density) and mycorrhiza $(\mathrm{F} \%, \mathrm{a} \%)$ parameters in the different heavy metal treatments

\begin{tabular}{|c|c|c|c|}
\hline \multirow{2}{*}{ Heavy metal } & Mycorrhiza & \multicolumn{2}{|c|}{ Trichoderma } \\
\cline { 3 - 4 } & parameters & Diversity & Density \\
\hline \multirow{3}{*}{$\mathrm{Cd}$} & \multirow{2}{*}{$\mathrm{F} \%$} & 0.345 & 0,407 \\
& & -0.965 & -0.600 \\
& \multirow{2}{*}{$\mathrm{a} \%$} & 0.537 & 0.821 \\
& & 0.333 & 0.842 \\
$\mathrm{Ni}$ & $\mathrm{F} \%$ & 0.620 & -0.345 \\
& & 0.892 & -0.940 \\
& $\mathrm{a} \%$ & 0.291 & -0.253 \\
& & 0.270 & -0.383 \\
$\mathrm{Zn}$ & $\mathrm{F} \%$ & -0.083 & $-0.996^{* *}$ \\
& & -0.013 & -0.998 \\
& $\mathrm{a} \%$ & 0.336 & -0.548 \\
& & 0.667 & -0.741 \\
\hline
\end{tabular}

Significance level of correlation coefficients is marked with asterisks as follows: $* * p<1 \%$. Note that there is no formal significance test for partial correlations.

${ }^{+}$Upper row contains correlation coefficients; the lower italic one contains partial correlation coefficients of given pairs of parameters when the effect of heavy metal was fixed. 
The effect of Zn pollution differed from that obtained for $\mathrm{Cd}$ and Ni. The correlation coefficients were found to be rather variable, in case of the significant finding, however the interrelation was always negative. Infection frequency of AM fungi (F\%) correlated negatively with the population density of Trichoderma fungi, especially with the abundance of $T$. viride. Arbusculum richness (a\%) was also negatively correlated by two other Trichoderma parameters, such as the frequency of two Trichoderma species. The partial correlation analysis has generally also supported these results, suggesting that there was a direct (negative) relationship between the colonization of Trichoderma and arbuscular mycorrhizal fungi in the $\mathrm{Zn}$-loaded soils.

\section{Multiple regression and partial correlation analysis between the Trichoderma and mycorrhiza parameters}

Due to the fact that several Trichoderma parameters showed correlation with mycorrhizal and plant parameters as single variables, their complex interactions were also tested with multiple regression analysis. In addition to the abundance of Trichoderma species, the data of their species diversity were also considered. Neither combination of Trichoderma parameters was sufficient enough, however, to describe the changes in infection percent of AM fungi in the various heavy metal treatments. Forcing the soil's available heavy metal content into the model made no improvement. It became very tight $\left(\mathrm{R}^{2}=0.998\right.$ at $\left.\mathrm{p}<0.0001\right)$, however, when the arbusculum richness $(\mathrm{a} \%)$ of the AM fungi was introduced. This finding for arbuscularity showed the real functioning of the arbuscular mycorrhizal fungi in the particular soil-plant ecosystems. The importance of AM fungi in the reduction of heavy metal stress is highlighted in this study. In the best model (Table 2) the constant remained the strongest variable, suggesting the omission of significant factor(s). However, the positive interaction between Trichoderma and AM fungi could be established. Among the Trichoderma parameters, the population density had an especially positive influence on the infection frequency (F\%) of AM fungi. There was a close negative

Table 2

Best multiple regression model for the infection frequency of arbuscular mycorrhiza fungi $\left(\mathrm{R}^{2}=0.9405\right.$ at $\left.\mathrm{p}=0.00062\right)$

\begin{tabular}{|l|c|c|c|}
\hline Variables & Coefficient & Significance level & MPCA coefficient* \\
\hline Constant & 77.670 & 0.0001 & - \\
Density & 0.766 & 0.001 & 0.952 \\
A\% & 0.831 & 0.0034 & 0.919 \\
\hline
\end{tabular}

Notes: Density $=$ Density of Trichoderma population; $\mathrm{A} \%=$ arbusculum richness in the mycorrhizal infected roots. ${ }^{*}$ Results of multiple partial correlation analysis carried out for parameters indicated in the table 
relationship, however between this Trichoderma parameter and arbusculum richness in multiple partial correlation analysis (Table 3). This model was built with similar steps as those for infection frequency. No significant model could be computed only from the Trichoderma parameters but introducing the infection frequency of the AM fungi (F\%) made an improvement (Table 3). Even in case of arbusculum richness the constant remained the strongest variable, suggesting that important inhibitory factors were left out of the model. Out of the seven examined Trichoderma parameters five have had a positive influence on the arbusculum richness of AM fungi.

Table 3

Best multiple regression model for the arbusculum richness of arbuscular mycorrhiza fungi $\left(\mathrm{R}^{2}=0.997\right.$ at $\left.\mathrm{p}=0.0007\right)$

\begin{tabular}{|l|c|c|c|}
\hline Variables & Coefficient & Significance level & MPCA coefficient* \\
\hline Constant & -68.904 & 0.0017 & - \\
Density & -5.411 & 0.0082 & -0.964 \\
F\% & 0.919 & 0.0012 & 0.990 \\
\hline
\end{tabular}

Notes: Density $=$ Density of Trichoderma population; F\% $=$ infection frequency of the arbuscular mycorrhizal fungi. * Results of multiple partial correlation analysis carried out for parameters indicated in the table

\section{Discussion}

The correlation between arbuscular mycorrhiza- and Trichoderma fungi in heavy metal treatments was studied. The long-term application of heavy metals under natural soil conditions provided a good possibility for the study of the colonization parameters of both indigenous fungal types. The various available heavy metal concentrations in the soil resulted in rather variable mycorrhiza colonization parameters, concomitant with the changes in the abundance and species composition of the indigenous Trichoderma population. Thus, statistical analyses of data presented here could give information on the relationships between Trichoderma and arbuscular mycorrhizal fungi. Such statistical analyses therefore can serve as a good tool for realizing the causative relations between microbes and can be used in considering the published data in this respect.

In some cases significant correlations were found between the colonizations of Trichoderma and AM fungi, which means that the indigenous Trichoderma population can influence mycorrhizal infection and functioning in metal-loaded soils.

Most of the correlations were further supported by partial correlation analysis (PCA). In some cases PCA coefficients were markedly higher than those of the "full" correlations. Results showed that the heavy metals used in 
this study might have an indirect effect on mycorrhization, through the alteration of the composition of rhizosphere microbiota.

Correlation data presented in this study indicated that not only the introduced, but the indigenous Trichoderma population too could effect mycorrhization considerably. Any factor altering the composition of Trichoderma species therefore may result also in an indirect influence on the mycorrhizal colonization in soil. In addition to several environmental stress factors, the competition for nutrients may also be the reason for the interactions between Trichoderma and arbuscular mycorrhiza fungi. BIRÓ et al. (1993) and GREEN et al. (1999) found that some organic amendment of the soil significantly stimulated the presence of beneficial fungi in the soils.

In respect of the correlations between the natural abundance of arbuscular mycorrhiza fungi and indigenous Trichoderma population, significant relationships were found. The value of these parameters, however, was greatly influenced by the type and loads of the heavy metals and by other multivariable soil-plant-climatic factors.

\section{Summary}

The abundance and diversity of indigenous Trichoderma fungi were tested for correlations with the natural colonization of symbiotic arbuscular mycorrhizal fungi (AMF) in Cd-, Zn- and Ni-polluted soils. Infection frequency (F\%) and arbusculum richness $(\mathrm{a} \%)$ of the mycorrhiza fungi were estimated on red clover grown in a pot experiment set up with calcareous loamy chernozem soil contaminated with $\mathrm{Cd}, \mathrm{Ni}$ and $\mathrm{Zn}$ salts (in 0, 30, 90 and $270 \mathrm{mg} \mathrm{kg}^{-1}$ dry soil concentration) in the field, eight years prior to the pot experiment.

Correlation analyses were used to assess the effect of different heavy metal loads on the interrelations of these two types of beneficial fungi. When the test was performed for single variables, significant correlations could be found with very close $(r>0.96$ at $p<0.05)$ results. The rate and direction (positive or negative) of correlations, however, varied with the type of heavy metals. With the combinations of some Trichoderma and mycorrhiza parameters a significant model was obtained for the infection frequency $\left(\mathrm{R}^{2}=0.9405\right.$ at $\left.\mathrm{p}=0.0062\right)$ and for arbusculum richness $\left(\mathrm{R}^{2}=0.997\right.$ at $\left.\mathrm{p}=0.0007\right)$, which suggests a significant complex influence between the symbiotic (AMF) and the free-living (Trichoderma) beneficial fungi. This interaction was altered by heavy metals. In the $\mathrm{Ni}$ treatments, the correlation data were always negative between the two groups of beneficial fungi.

Key words: Trichoderma, mycorrhiza, interactions, heavy metals 
The presented study was supported by the National Scientific Research Fund (OTKA Project F025924, F034665), the EU-Kp5 Program (MYCOREM project) and the activity of COST Action 838 .

\section{References}

ASKEW, D. J. \& LAING, M. D., 1993. An adapted selective medium for the quantitative isolation of Trichoderma species. Plant Pathol. 42. 686-690.

BIRÓ, B. et al., 1993. Symbiont effect of Rhizobium bacteria and VAM fungi on Pisum sativum in recultivated mine spoils. Geomicrobiol. J. 11. 275-284.

BissetT, J., 1991a. A revision of the genus Trichoderma. II. Infrageneric classification. Can. J. Bot. 69. 2357-2372.

BISSETT, J., 1991b. A revision of the genus Trichoderma. III. Section Pachybasium. Can. J. Bot. 69. 2373-2417.

BisSeTt, J., 1991c. A revision of the genus Trichoderma IV. Additional notes on section Longibrachiatum. Can. J. Bot. 69. 2418-2420.

BISSET, J., 1992. Trichoderma atroviride. Can. J. Bot. 70. 639-641.

CAlvet, C., Pera, J. \& BAREA, J. M., 1992. Interactions of Trichoderma spp. with Glomus mosseae and two wilt pathogenic fungi. Agric. Ecosyst. Environ. 29. 5966.

GODEAS, A. et al., 1999. Influence of soil impoverishment on the interaction between Glomus mosseae and saprobe fungi. Mycorrhiza. 9. 185-189.

GREEN, H. et al., 1999. Suppression of the biocontrol agent Trichoderma harzianum by mycelium of the arbuscular mycorrhizal fungus Glomus intraradices in root-free soil. Appl. Environ. Microbiol. 65. 1428-1434.

GRYNDLER, M., HRŠELOVÁ, H. \& CHVÁTALOVÁ, I., 1996. Effect of free-soil-inhabiting or root-associated microfungi on the development of arbuscular mycorrhizae and proliferation of intraradical mycorrhizal hyphae. Folia Microbiol. 41. 193-196.

KÁDÁR, I., 1995. Contamination of the Soil-Plant-Animal-Human Foodchain with Chemical Elements in Hungary. (In Hungarian) RISSAC. Budapest.

KREDICS, L. et al., 2001a. Effect of heavy metals on growth and extracellular enzyme activities of mycoparasitic Trichoderma strains. Bull. Environ. Contam. Toxicol. 66. $249-254$.

KREDICS, L. et al., 2001b. Isolation and characterization of heavy metal resistant mutants from mycoparasitic Trichoderma strains. IOBC-WPRS Bull. 24. 233-236.

KREDICS, L. et al., 2001c. Breeding of mycoparasitic Trichoderma strains for heavy metal resistance. Lett. Appl. Microbiol. 33. 112-116.

PAPAVIZAS, G. C., 1985. Trichoderma and Gliocladium: biology, ecology, and potential for biocontrol. Annu Rev. Phytopathol. 23. 23-54.

RifAI, M. A., 1969. A revision of the genus Trichoderma. Mycol. Papers, Commonw. Mycol. Inst. 116. 1-56.

RousseaU A. et al., 1996 Mycoparasitism of the extramatrical phase of Glomus intraradices by Trichoderma harzianum. Phytopathology 86. 434-443. 
TSMILLI-MiCHAEL M. et al., 2000. Synergistic and antagonistic effects of AM fungi and Rhizobium and Azospirillum nitrogen-fixers on the photosynthetic activity of alfalfa, probed by the chlorophyll $a$ polyphasic_fluorescence transient_O-J-I-P. J. Appl. Soil Ecol. 15. 169-182.

VÖRÖs, I. et al., 1998. Effect of AM fungi on the heavy metal toxicity to Trifolium pratense in soils contaminated with $\mathrm{Cd}, \mathrm{Zn}$ and Ni salts. Agrokémia és Talajtan. 47. 277-289.

Wyss, P., Boller, T. H. \& WiemKen, A., 1992. Testing the effect of biological control agents on the formation of vesicular arbuscular mycorrhiza. Plant \& Soil. 147. $159-162$. 